\title{
Association between air pollution and suicide: a time series analysis in four Colombian cities
}

\author{
Julián Alfredo Fernández-Niño', Claudia Iveth Astudillo-García², Laura Andrea Rodríguez-Villamizar ${ }^{3}$ \\ and Víctor Alfonso Florez-Garcia ${ }^{1}$
}

\begin{abstract}
Background: Recent epidemiological studies have suggested that air pollution could be associated with suicide. However, other studies have criticized these results for being analytically weak and not taking into account potential confounding factors. As such, further studies examining the relationship under diverse contexts are necessary to help clarify this issue. This study explored the association between specific air pollutants $\left(\mathrm{NO}_{2}, \mathrm{SO}_{2}, \mathrm{PM}_{10}, \mathrm{PM}_{2.5}, \mathrm{CO}\right.$ and $\left.\mathrm{O}_{3}\right)$ and suicide incidence in four Colombian cities after adjusting for climatic variables and holidays.

Methods: A time series of daily suicides among men and women living in Bogota, Medellin, Cali and Bucaramanga was generated using information from the National Administrative Department of Statistics (DANE) for the years 2011-2014. At the same time, the average daily concentration of each air pollutant for each city was obtained from monitoring stations belonging to the National Air Quality Surveillance System. Using this information together, we generated conditional Poisson models (stratified by day, month and year) for the suicide rate in men and women, with air pollutants as the principal explanatory variable. These models were adjusted for temperature, relative humidity, precipitation and holidays.

Results: No association was found between any of the examined pollutants and suicide: $\mathrm{NO}_{2}$ (IRR:0.99, 95\% Cl: 0.95-1.04), SO $\mathrm{SO}_{2}$ (IRR:0.99, 95\% Cl: 0.98-1.01), PM10 (IRR:0.99, 95\% Cl:0.95-1.03), PM 2.5 (IRR:1.01, 95\% Cl: 0.98-1.05), CO (IRR:1.00, 95\% Cl:1.00-1.00) and $\mathrm{O}_{3}$ (IRR: 1.00, 95\% Cl: 0.96-1.04). In the same way, no association was found in stratified models by sex and age group neither in lagged and cumulative effects models.

Conclusions: After adjusting for major confounding factors, we found no statistically significant association between air pollution and suicide in Colombia. These "negative" results provide further insight into the current discussion regarding the existence of such a relationship.
\end{abstract}

Keywords: Suicide, Air pollution, Confounding factors, Epidemiology

\section{Background}

In 2015 , approximately 788,000 individuals committed suicide worldwide, which is equivalent to an age-standardized rate of 10.7 individuals per 100,000 inhabitants [1]. In the 15-29 year age group, suicide was the second leading cause of death [2]. As such, suicide currently poses a very important public health problem, especially in developing countries where the rate is increasing [1].

\footnotetext{
* Correspondence: claudiaiveth.astudillo@gmail.com

${ }^{2}$ Servicios de Atención Psiquiátrica, Secretaría de Salud, Ciudad de México, Mexico

Full list of author information is available at the end of the article
}

In Colombia, there were 24,882 suicides between 2000 and 2010, which means an average of 6.2 per day that increases up to 8.0 per day in holidays. Despite the suicide rates have shown a downward trend since 2000, suicides remain a major challenge, as $50 \%$ of them are committed by people under 31 years old [3].

Suicide is a very complex and multifactorial event, with risk factors existing at both the individual and contextual level [2]. Since the nineteenth century, the effect of environmental determinants on suicide has been widely investigated $[4,5]$. For instance, meteorological factors such as rain, increases in temperature and drought, have been closely related with seasonal behaviors of suicide in certain

(C) The Author(s). 2018 Open Access This article is distributed under the terms of the Creative Commons Attribution 4.0 International License (http://creativecommons.org/licenses/by/4.0/), which permits unrestricted use, distribution, and 
countries [6, 7]. More recently, environmental pollution, specifically air pollution, has been proposed as another determinant of suicide incidence at the ecological level [8-12].

Although the harmful effects of air pollution are mainly associated with respiratory and cardiovascular diseases [13], more recent evidence also points towards adverse effects for the central nervous system. According to the hypothesis of neuroinflammation, air contaminants could cause an increase in cytokines and reactive oxygen species, and consequently self-aggressive behavior $[14,15]$. The causal mechanisms between air pollution and suicide might not only involve this direct pathway via inflammation, but also the exacerbation of mental disorders that increase the risk of suicidal behavior $[16,17]$. Nonetheless, these pathways are not yet clearly established, and are far from being biologically proven.

Due to poor methodological support and possible confounding factors, the epidemiological associations between air pollution and suicide are quite controversial and inconclusive [18-20]. As such, it is important not only to further explore this relationship in other socioenvironmental contexts, but also to adjust for the main confounding factors. For instance, as shown in several studies, climate itself can be associated with pollution levels [18-20]. Furthermore, as in other air quality and health studies, the use of appropriate statistical techniques is highly important to control for seasonality and autocorrelation of observations [19, 21].

A recent systematic review suggests a certain consistency in the association between air pollution and suicide [22]. However, the conclusions of this review should be taken with caution because when a new epidemiological association is reported, it is well known that there is a tendency to first publish the "positive" results. This leads to a publication bias and as such, an undesirable impact on the conclusions of systematic reviews and meta-analyses [23]. Thus, the replication and publication of rigorous studies, even those with "negative" results, enables clarification of the relationships and avoids potential biases.

This study explored the relationship between air pollution and suicide incidence in four capital cities of Colombia. Specifically, we consider the mass concentrations of nitrogen dioxide $\left(\mathrm{NO}_{2}\right)$, sulfur dioxide $\left(\mathrm{SO}_{2}\right)$, carbon monoxide $(\mathrm{CO})$, ozone $\left(\mathrm{O}_{3}\right)$, and particulate material with aerodynamic diameters less than 10 and 2 . $5 \mu \mathrm{m}\left(\mathrm{PM}_{10}\right.$, and $\mathrm{PM}_{2.5}$, respectively), and adjusted our results according to weather conditions and holidays.

\section{Methods}

\section{Study type and observation units}

We conducted a multi-city ecological time series study in which the unit of observation was city/day. We included four of the five main capital cities of Colombia (Bogota, Bucaramanga, Cali, and Medellin) because they had daily air pollutant measurements available for the entire four-year study period (January 1, 2011 to December 31, 2014).

\section{Variables and data sources Outcome: suicide counts}

For each city, the number of suicides per day were calculated taking into account the following ICD-10 codes as the principal cause of death: X60-X84 and Y87.0. This data was obtained from the mortality database of the National Department of Statistics (DANE) for the indicated study period. The total population of each city, which was obtained as a projection based on DANE data for each year, was considered as the exposure variable in our analyses. As the total population of a city hardly changes over the course of a year, our analyses enable comparisons of the suicide counts between years, and more importantly, between cities.

\section{Exposure variable: air pollution}

Daily data from the National Air Quality Surveillance System was obtained for the following air pollutants: $\mathrm{CO}, \mathrm{NO}_{2}, \mathrm{SO}_{2}, \mathrm{O}_{3}, \mathrm{PM}_{10}$ and $\mathrm{PM}_{2.5}$. These measurements were obtained from the air quality monitoring stations located across the four cities: 13 in Bogota, 7 in Medellin, 5 in Cali and 4 in Bucaramanga. For each city, we calculated the daily averages for $\mathrm{NO}_{2}$, $\mathrm{PM}_{10}, \mathrm{PM}_{2.5}$, and $\mathrm{SO}_{2}$, and the maximum 8-h moving averages for $\mathrm{CO}$ and $\mathrm{O}_{3}$, by averaging information from all monitoring stations.

\section{Confounders}

The main confounding factors were meteorological variables and holidays. Daily meteorological data regarding temperature (in degrees Celsius), relative humidity (\%), and precipitation (in $\mathrm{mm}$ ) were obtained from 19 meteorological stations (11 in Bogota, 4 in Medellin, 2 in Cali, and 2 in Bucaramanga) located in different points across the four cities. This information was obtained from the Institute of Hydrology, Meteorology and Environmental Studies (IDEAM, by its initials in Spanish). For the analysis of holidays, we generated an indicator variable as follows: ordinary day (reference category), holiday, and long weekend (this last one refers to a Colombia tradition that there are weekends with non-working Mondays given by the relocation of some holidays). As holidays change according to the year, historical calendars were used to retrieve the relevant information. 


\section{Statistical analysis}

We generated a description of the daily suicide rates by city. By using the dispersion index (VIT) [24] and the asymptotic Böhning test [25], we verified the equidispersion assumption (i.e., the null hypothesis of a Poisson distribution could not be rejected; $p>0.20$ ). For each time series, a Dickey Fuller test was performed to explore the existence of a unitary root, which is typical of a non-stationary model.

The association between air quality and suicides was explored by using a multi-city Poisson model conditioned by time strata (grouping by day, month and year) to control for the seasonality of suicide data. In this way, effects are estimated considering the structure of the correlation that the observations would have when they are generated on the same stratum of day of the week, month, and year [26], with the city as an indicator variable by using the following fixed effect model:

$$
\begin{aligned}
\operatorname{Ln}\left(Y_{i, s}\right)= & B_{s}+B_{1} X_{1 i}+B_{2} X_{2 i}+B_{3} X_{3 i}+B_{4} X_{4 i} \\
& +B_{5} X_{5 i}+B_{6} X_{6}+\operatorname{Ln}(\lambda), Y \approx \operatorname{Poisson}\left(\mu_{i}\right)
\end{aligned}
$$

Where $\mathrm{Y}_{\mathrm{i}, \mathrm{s}}$ is the suicide count in the day $\mathrm{i}$ that falls in stratum $\mathrm{s}, \mathrm{X}$ is the vector of independent variables: $\mathrm{X}_{1}$ air pollutant; $\mathrm{X}_{2}$ temperature $\mathrm{X}_{3}$ relative humidity, $\mathrm{X}_{4}$ precipitation, $\mathrm{X}_{5}$ holidays indicador, $\mathrm{X}_{6}$ city indicator, and $\lambda$ is the exposure variable (population) with coefficient forced to be 1 .

These conditional time series models allow for adequate control of the seasonality of the variables under analysis. Moreover, they require lower computational intensity compared to other time series models, and yield similar estimation results to those that would be obtained using a case-crossover model for analysis of individuals [27].

In order to facilitate interpretation, the daily concentrations of the pollutants were centered by the integer value that approximately corresponds to $20 \%$ of the average concentration of each pollutant in the time series. With respect to $\mathrm{PM}_{10}$ and $\mathrm{PM}_{2.5}$, the values were centered by convention on 10 and $5 \mu \mathrm{g} / \mathrm{m}^{3}$, respectively. Models were stratified by sex and age group (Children under 15 years old, adults from 15 to 60 years and older adults aged 60 years and over). Finally, with the objective of exploring potential lagged effects, single lagged effects were explored from 1 up to 7 days and cumulative effects were explored for moving average estimates of lagged days 1 to 7 by using fixed models at city level without conditioning by time strata. Fixed models were chosen at the city level since, when performing the Hausman test, slight systematic differences were found between the estimators obtained from the fixed effects model and those estimated using random effects for the city. This decision was made given that the estimates of fixed effects are more unbiased than those of random effects.

Associations were considered statistically significant at an alpha of 0.05 with a Bonferroni correction given as $\alpha / \mathrm{m}$ where $\mathrm{m}$ is the number of hypothesis in each analysis. All models were adjusted by temperature,
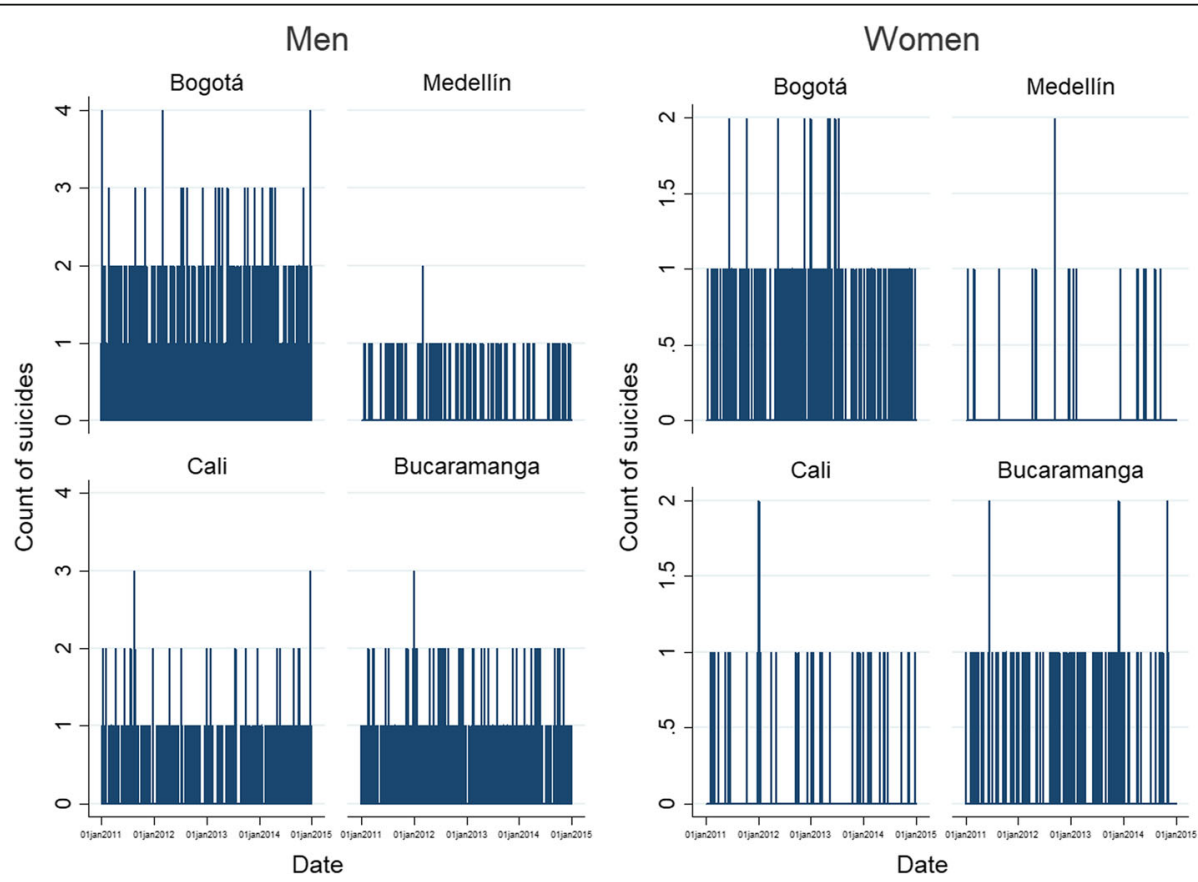

Fig. 1 Daily suicide counts by sex in four Colombian cities, 2011-2014 


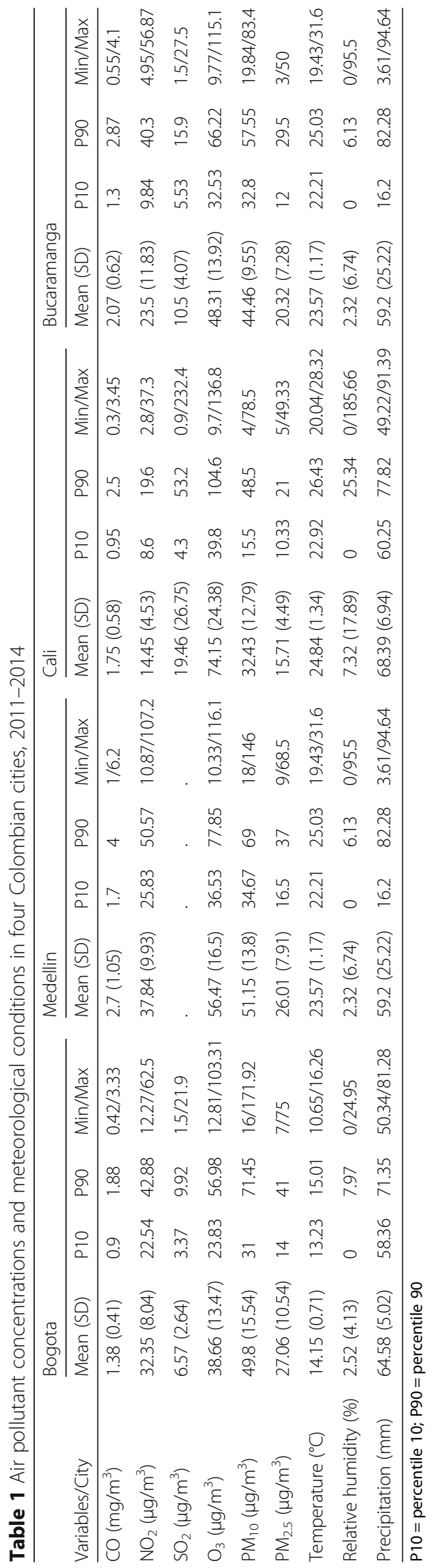


relative humidity and holidays. Models were evaluated using the distribution of residuals and the goodness of fit tests. All analyses were performed using STATA 14 (Stata Corporation, College Station, TX, USA) (26).

\section{Results}

Over the entire study period, there were a total of 1942 suicides (average of 1.37 per day) in the four cities: 1000 suicides occurred in Bogota (808 of whom were males), 133 in Medellin (95 males), 311 in Cali (266 males) and 498 in Bucaramanga (387 males). Figure 1 shows the daily number of suicides over the entire study period by sex and city. In Bogota, the average number of suicides per day was 0.68 (95\% CI: 0.64-0.73), with a variance of 0.72 . Medellin on the other hand, was the city with the lowest daily average number of suicides and variance, with values of 0.08 (95\% CI: $0.06-0.09$ ) and 0.08 , respectively. In the case of Cali, the daily average number of suicides was estimated at 0.21 (95\% CI: 0.19-0.24), with a variance of 0.22 . Finally, the average daily suicide counts for Bucaramanga was 0.34 (95\% CI: 0.31-0,37), with a variance of 0.32 .

In all cities, the low daily averages can be attributed to the high proportion of days in which zero suicides were registered. In fact, of the 1461 days considered in this study, 51.47, 92.47, 81.11, and $70.70 \%$ of them had no suicides in Bogotá, Medellin, Cali, and Bucaramanga, respectively. Using equi-dispersion tests, we proved that the behavior of the daily counts for each city were as expected according to a Poisson distribution. The Dickey-Fuller test rejected the unit root hypothesis, thereby suggesting a stationary behavior in all four cities. Descriptive data for air pollutants concentrations and meteorological data by city is presented in Table 1 .

Missing data were excluded from the analysis. However, we did not used any imputation method as we obtained a validated database for air pollutants concentration from the National Government with daily pollutant concentration values for nearly all of the 1461 days in the time-series, with the exception of PM2.5 (3\% of the series was missing data in Medellin, 7\% in Bogota, 5\% in Bucaramanga and Cali).

Table 2 presents the conditional, multi-city Poisson models for total suicides, and suicides by gender for each pollutant. At first, spurious statistically significant associations were found in the crude models (i.e., not adjusted by holidays or climatic variables) for $\mathrm{NO}_{2}, \mathrm{PM}_{10}, \mathrm{PM}_{2.5}$ and $\mathrm{CO}$. In contrast, the estimates that take into account the confounding factors suggest that none of the pollutants are significantly associated with total suicide count or suicide counts by sex $(p>0.05)$. Estimators adjusted by temperature, precipitation, relative humidity and holidays for total suicides obtained from the conditional Poisson model for each air pollutant were non statistically significant: $\mathrm{NO}_{2}$ (IRR:0.99, 95\% CI: 0.95-1.04), $\mathrm{SO}_{2}$
Table 2 Conditional Poisson regression models for suicide counts among four Colombian cities, 2011-2014

\begin{tabular}{|c|c|c|c|c|c|c|c|c|}
\hline \multirow[t]{2}{*}{ Pollutant } & \multicolumn{4}{|c|}{ Crude Estimations } & \multicolumn{4}{|c|}{ Adjusted Estimations ${ }^{a}$} \\
\hline & \multirow{2}{*}{$\begin{array}{l}\overline{\text { IRR }} \\
\text { otal } n\end{array}$} & \multicolumn{2}{|c|}{$95 \% \mathrm{Cl}$} & \multirow[t]{2}{*}{$p$} & \multirow[t]{2}{*}{$\overline{\mathrm{IRR}}$} & \multicolumn{2}{|c|}{$95 \% \mathrm{Cl}$} & \multirow[t]{2}{*}{$\mathrm{p}$} \\
\hline \multicolumn{5}{|c|}{ Models for total number of suicides } & & & & \\
\hline $\mathrm{NO}_{2}$ & 0.82 & 0.80 & 0.85 & $<0.01$ & 0.99 & 0.95 & 1.04 & 0.81 \\
\hline $\mathrm{SO}_{2}$ & 1.00 & 0.99 & 1.01 & 0.52 & 0.99 & 0.98 & 1.01 & 0.31 \\
\hline $\mathrm{PM}_{10}$ & 0.96 & 0.93 & 0.99 & $<0.01$ & 0.99 & 0.95 & 1.03 & 0.64 \\
\hline $\mathrm{PM}_{2.5}$ & 0.95 & 0.92 & 0.98 & $<0.01$ & 1.01 & 0.98 & 1.05 & 0.47 \\
\hline $\mathrm{CO}_{\max }$ & 0.99 & 0.99 & 0.99 & $<0.01$ & 1.00 & 1.00 & 1.00 & 0.81 \\
\hline $\mathrm{O}_{3}$ & 1.00 & 0.98 & 1.03 & 0.851 & 1.00 & 0.96 & 1.04 & 0.93 \\
\hline \multicolumn{9}{|c|}{ Models for suicides among men } \\
\hline $\mathrm{NO}_{2}$ & 0.82 & 0.80 & 0.85 & $<0.01$ & 0.99 & 0.94 & 1.04 & 0.69 \\
\hline $\mathrm{SO}_{2}$ & 1.00 & 1.00 & 1.01 & 0.34 & 0.99 & 0.98 & 1.01 & 0.35 \\
\hline $\mathrm{PM}_{10}$ & 0.96 & 0.93 & 0.99 & 0.02 & 1.00 & 0.95 & 1.04 & 0.86 \\
\hline $\mathrm{PM}_{2.5}$ & 0.95 & 0.92 & 0.98 & $<0.01$ & 1.00 & 0.97 & 1.04 & 0.80 \\
\hline $\mathrm{CO}_{\max }$ & 0.99 & 0.98 & 0.99 & $<0.01$ & 1.00 & 1.00 & 1.00 & 0.69 \\
\hline $\mathrm{O}_{3}$ & 1.01 & 0.98 & 1.03 & 0.65 & 1.00 & 0.96 & 1.04 & 0.93 \\
\hline \multicolumn{9}{|c|}{ Models for suicides among women } \\
\hline $\mathrm{NO}_{2}$ & 0.82 & 0.76 & 0.88 & $<0.01$ & 1.01 & 0.92 & 1.12 & 0.77 \\
\hline $\mathrm{SO}_{2}$ & 0.99 & 0.97 & 1.02 & 0.64 & 0.99 & 0.96 & 1.03 & 0.69 \\
\hline $\mathrm{PM}_{10}$ & 0.95 & 0.88 & 1.02 & 0.18 & 0.97 & 0.88 & 1.06 & 0.47 \\
\hline $\mathrm{PM}_{2.5}$ & 0.94 & 0.88 & 1.01 & 0.08 & 1.00 & 0.93 & 1.09 & 0.92 \\
\hline $\mathrm{CO}_{\max }$ & 0.99 & 0.98 & 0.99 & $<0.01$ & 1.00 & 0.99 & 1.01 & 0.77 \\
\hline $\mathrm{O}_{3}$ & 0.99 & 0.93 & 1.04 & 0.62 & 1.00 & 0.91 & 1.09 & 0.93 \\
\hline
\end{tabular}

For each pollutant the IRR are mean changes in the rates per increase in this $20 \%$ of the average $\left(6 \mu \mathrm{g} / \mathrm{m}^{3}\right.$ for $\mathrm{NO}_{2}, 2 \mu \mathrm{g} / \mathrm{m}^{3}$ for $\mathrm{SO}_{2}, 0.4 \mu \mathrm{g} / \mathrm{m} 3$ for $\mathrm{CO}$ and $10 \mu \mathrm{g} / \mathrm{m}^{3}$ for $\mathrm{O}_{3}$ ). For $\mathrm{PM}_{10}$ and $\mathrm{PM}_{2.5}$, the values were centered by convention on 10 and $5 \mu \mathrm{g} / \mathrm{m}^{3}$, respectively

IRR incidence rate ratio, $\mathrm{Cl}$ confidence interval

${ }^{a}$ Estimates are adjusted for temperature, precipitation, humidity and holidays

(IRR:0.99, 95\% CI: 0.98-1.01), PM 10 (IRR:0.99, 95\% CI:0. 95-1.03), $\quad \mathrm{PM}_{2.5} \quad$ (IRR:1.01, 95\% CI: 0.98-1.05), $\mathrm{CO}_{\mathrm{Max}}$ (IRR:1.00, 95\% CI:1.00-1.00) and $\mathrm{O}_{3}$ (IRR: 1.00, 95\% CI: 0.96-1.04).

Similarly, these associations were not found to be statistically significant after stratifying by sex and age group (Table 3 ). Moreover, single day and 7-day cumulative lagged effects were not found statistically significant in men neither in women (Table 4).

\section{Discussion}

In this study, we did not find any statistically significant association between daily air pollutant concentrations and the daily number of suicides in four Colombian cities. However, we did find significant "crude" associations when the preliminary data had not yet been adjusted for confounding factors, even when using a model that recognizes self-correlation of observations. Thus, these results suggest that some previous studies 
Table 3 Conditional Poisson regression models for suicides among four Colombian cities stratified by sex and age group, 2011-2014

\begin{tabular}{|c|c|c|c|c|c|c|c|c|c|c|c|c|c|}
\hline \multirow{3}{*}{$\begin{array}{l}\text { Sex } \\
\text { Men }\end{array}$} & \multirow{3}{*}{$\begin{array}{l}\text { Pollutant } \\
\mathrm{NO}_{2}\end{array}$} & \multicolumn{4}{|c|}{ Children } & \multicolumn{4}{|c|}{ Adults } & \multicolumn{4}{|c|}{ Older adults } \\
\hline & & \multirow{2}{*}{$\frac{\mathrm{IRR}}{1.08}$} & \multicolumn{2}{|c|}{$95 \% \mathrm{Cl}$} & \multirow{2}{*}{$\frac{p}{0.62}$} & \multirow{2}{*}{$\frac{\mathrm{IRR}}{0.98}$} & \multicolumn{2}{|c|}{$95 \% \mathrm{Cl}$} & \multirow{2}{*}{$\frac{p}{0.45}$} & \multirow{2}{*}{$\frac{\text { IRR }}{1.04}$} & \multicolumn{2}{|c|}{$95 \% \mathrm{Cl}$} & \multirow{2}{*}{$\frac{p}{0.57}$} \\
\hline & & & 0.79 & 1.47 & & & 0.93 & 1.03 & & & 0.90 & 1.21 & \\
\hline & $\mathrm{SO}_{2}$ & 0.70 & 0.53 & 1.04 & 0.16 & 0.99 & 0.98 & 1.00 & 0.39 & 1.00 & 0.82 & 1.35 & 0.68 \\
\hline & $\mathrm{PM}_{10}$ & 0.89 & 0.67 & 1.19 & 0.44 & 0.99 & 0.94 & 1.04 & 0.72 & 1.04 & 0.92 & 1.18 & 0.53 \\
\hline & $\mathrm{PM}_{2.5}$ & 0.97 & 0.76 & 1.23 & 0.79 & 1.00 & 0.96 & 1.04 & 0.96 & 1.14 & 1.02 & 1.28 & $0.02^{\mathrm{a}}$ \\
\hline & $\mathrm{CO}_{\max }$ & 1.00 & 0.98 & 1.03 & 0.62 & 1.00 & 1.00 & 1.00 & 0.45 & 1.00 & 0.99 & 1.01 & 0.57 \\
\hline & $\mathrm{O}_{3}$ & 0.91 & 0.70 & 1.19 & 0.51 & 1.00 & 0.96 & 1.06 & 0.88 & 0.99 & 0.88 & 1.12 & 0.90 \\
\hline \multirow[t]{6}{*}{ Women } & $\mathrm{NO}_{2}$ & 0.56 & 0.30 & 1.01 & 0.10 & 1.05 & 0.95 & 1.17 & 0.36 & 0.95 & 0.66 & 1.38 & 0.80 \\
\hline & $\mathrm{SO}_{2}$ & 0.66 & 0.39 & 1.14 & 0.14 & 1.00 & 0.96 & 1.04 & 0.96 & 0.93 & 0.79 & 1.09 & 0.38 \\
\hline & $\mathrm{PM}_{10}$ & 0.60 & 0.35 & 1.03 & 0.06 & 0.97 & 0.88 & 1.08 & 0.60 & 1.05 & 0.82 & 1.35 & 0.68 \\
\hline & $\mathrm{PM}_{2.5}$ & 0.79 & 0.53 & 1.16 & 0.23 & 1.00 & 0.92 & 1.09 & 0.97 & 1.17 & 0.96 & 1.43 & 0.13 \\
\hline & $\mathrm{CO}_{\max }$ & 0.96 & 0.92 & 1.00 & 0.06 & 1.00 & 1.00 & 1.01 & 0.36 & 1.00 & 0.97 & 1.02 & 0.80 \\
\hline & $\mathrm{O}_{3}$ & 1.21 & 0.73 & 1.99 & 0.45 & 0.99 & 0.90 & 1.09 & 0.83 & 0.97 & 0.76 & 1.25 & 0.84 \\
\hline
\end{tabular}

For each pollutant the IRR are mean changes in the rates per increase in this $20 \%$ of the average $\left(6 \mu \mathrm{g} / \mathrm{m}^{3}\right.$ for $\mathrm{NO}_{2}, 2 \mu \mathrm{g} / \mathrm{m}^{3}$ for SO${ }_{2}, 0.4 \mu \mathrm{g} / \mathrm{m}^{3}$ for CO and $10 \mu \mathrm{g} / \mathrm{m}^{3}$ for $\left.\mathrm{O}_{3}\right)$. For $\mathrm{PM}_{10}$ and $\mathrm{PM}_{2.5}$, the values were centered by convention on 10 and $5 \mu \mathrm{g} / \mathrm{m}^{3}$, respectively

IRR incidence rate ratio, $\mathrm{Cl}$ confidence interval

Estimates are adjusted for temperature, precipitation, humidity and holidays

${ }^{a}$ No significant considering Bonferroni correction

could have inaccurately reported positive associations when omitting important confounding factors, a possibility that has also been pointed out in other studies $[18,19]$.

The previous studies that reported a significant association between air pollution and suicide rate are relatively heterogeneous in terms of the air pollutants involved. For example, while none of the studies that evaluated the effects of $\mathrm{CO}[9,11]$ found an association, three out of five studies examining $\mathrm{NO}_{2}[8,10,12]$ found an association, and only one study reported an association with $\mathrm{SO}_{2}$ [9]. In contrast, all three studies that evaluated the effects of $\mathrm{O}_{3}[9,11,28]$ consistently found an association. Furthermore, with respect to PM, five out of the six studies found an association (including $\mathrm{PM}_{10}$ and $\mathrm{PM}_{2.5}$ ) [9-12, 29]. In this study we did not found any association of suicide counts and air pollutants concentrations after controlling for meteorological factors and the influence of holidays.

In some of the previous studies, associations were only found within specific age groups [10]. Likewise, in the studies by Bakian et al. [12] and Kim et al. [29], an association was only found in men and individuals with cardiovascular disease, respectively. Here, although we did not specifically explore the effect on individuals with underlying health conditions, no differences in the results were found when examining the data by age group or gender. Furthermore, Lin et al. [10] reported that there could be an interaction between the different levels of pollution, the mixture of pollutants, and/or specific factors of the population, and that such interactions could explain why associations appear in some populations but not others. Thus, it would be interesting to further investigate such potential interactions in future studies.

It is important to note that our study has the typical limitations of ecological approaches and estimations and conclusions can be only interpreted at population level as individual heterogeneity is not taken into account. For example, although not explored in our study, individual susceptibility to air pollution or other conditions such as interactions with other allergens could have an impact on associations, which have been reported in other studies [22]. Moreover, related to the abovementioned limitation is the fact that analyses based on broad geographic areas such as cities (as is the case with most studies that analyze the effect of air pollution on health) do not consider relationships on a smaller scale. That is, our estimations are based on the city average of pollutant concentrations, meteorological variables and on the total daily suicide number. Despite the fact that there are an important number of air quality and meteorological stations across cities, they are not necessarily distributed randomly over the entire study areas, and thus a sociological fallacy could be incurred [30]. Therefore, as the results of this study are applied on a population level, they cannot be extrapolated to the individual or small-area level.

In Colombia, DANE official mortality records and verified and validate by experts in death codifications system and is estimated that accounts for approximately $95 \%$ of the deaths in urban areas. However, It is also 
Table 4 Models with lagged and cumulative effects for suicides among four Colombian cities stratified by sex, 2011-2014

\begin{tabular}{|c|c|c|c|c|c|c|c|c|c|}
\hline \multirow{3}{*}{$\begin{array}{l}\text { Pollutant } \\
\mathrm{NO}_{2}\end{array}$} & \multicolumn{5}{|l|}{ Men } & \multicolumn{4}{|c|}{ Women } \\
\hline & \multirow{2}{*}{$\begin{array}{l}\text { Lag } \\
\text { LO }\end{array}$} & \multirow{2}{*}{$\frac{\text { IRR }}{0.98}$} & \multicolumn{2}{|c|}{$95 \% \mathrm{Cl}$} & \multirow{2}{*}{$\frac{p}{0.61}$} & \multirow{2}{*}{$\begin{array}{l}\text { IRR } \\
0.98\end{array}$} & \multicolumn{2}{|c|}{$95 \% \mathrm{Cl}$} & \multirow{2}{*}{$\frac{p}{0.79}$} \\
\hline & & & 0.92 & 1.05 & & & 0.86 & 1.12 & \\
\hline & L1 & 0.96 & 0.89 & 1.03 & 0.25 & 1.00 & 0.86 & 1.17 & 0.96 \\
\hline & L2 & 1.02 & 0.95 & 1.10 & 0.61 & 0.97 & 0.83 & 1.13 & 0.69 \\
\hline & L3 & 1.05 & 0.98 & 1.14 & 0.18 & 1.05 & 0.90 & 1.22 & 0.57 \\
\hline & L4 & 1.06 & 0.98 & 1.14 & 0.16 & 1.18 & 1.01 & 1.37 & $0.03^{\mathrm{a}}$ \\
\hline & L5 & 0.93 & 0.87 & 1.01 & 0.09 & 1.03 & 0.88 & 1.20 & 0.71 \\
\hline & L6 & 1.00 & 0.93 & 1.08 & 0.95 & 0.94 & 0.80 & 1.09 & 0.41 \\
\hline & L7 & 1.00 & 0.93 & 1.06 & 0.89 & 0.96 & 0.84 & 1.09 & 0.50 \\
\hline & L1-7 & 0.99 & 0.93 & 1.04 & 0.61 & 1.06 & 0.95 & 1.19 & 0.27 \\
\hline \multirow[t]{9}{*}{$\mathrm{SO}_{2}$} & LO & 1.02 & 0.97 & 1.07 & 0.51 & 0.96 & 0.85 & 1.08 & 0.47 \\
\hline & L1 & 0.95 & 0.89 & 1.01 & 0.07 & 0.96 & 0.84 & 1.09 & 0.52 \\
\hline & L2 & 0.97 & 0.92 & 1.03 & 0.35 & 0.98 & 0.86 & 1.11 & 0.73 \\
\hline & L3 & 1.05 & 0.99 & 1.11 & 0.09 & 1.05 & 0.92 & 1.19 & 0.50 \\
\hline & L4 & 0.98 & 0.92 & 1.04 & 0.49 & 1.06 & 0.93 & 1.21 & 0.36 \\
\hline & L5 & 1.03 & 0.98 & 1.09 & 0.26 & 0.99 & 0.86 & 1.13 & 0.83 \\
\hline & L6 & 0.96 & 0.91 & 1.02 & 0.18 & 0.97 & 0.85 & 1.11 & 0.65 \\
\hline & L7 & 1.01 & 0.96 & 1.06 & 0.71 & 0.96 & 0.85 & 1.08 & 0.47 \\
\hline & L1-7 & 1.00 & 0.98 & 1.00 & 0.15 & 0.99 & 0.96 & 1.03 & 0.63 \\
\hline \multirow[t]{9}{*}{$\mathrm{PM}_{10}$} & LO & 0.96 & 0.92 & 1.02 & 0.18 & 1.00 & 0.90 & 1.12 & 0.93 \\
\hline & L1 & 1.01 & 0.95 & 1.07 & 0.83 & 0.96 & 0.85 & 1.09 & 0.55 \\
\hline & L2 & 0.98 & 0.92 & 1.04 & 0.51 & 0.99 & 0.88 & 1.12 & 0.87 \\
\hline & L3 & 1.04 & 0.99 & 1.11 & 0.13 & 1.02 & 0.91 & 1.14 & 0.70 \\
\hline & L4 & 1.05 & 0.99 & 1.12 & 0.08 & 1.12 & 0.99 & 1.25 & $0.06^{a}$ \\
\hline & L5 & 0.98 & 0.92 & 1.04 & 0.43 & 0.92 & 0.82 & 1.05 & 0.22 \\
\hline & L6 & 0.99 & 0.93 & 1.05 & 0.68 & 1.00 & 0.88 & 1.13 & 0.94 \\
\hline & L7 & 0.99 & 0.94 & 1.04 & 0.72 & 0.98 & 0.88 & 1.09 & 0.67 \\
\hline & L1-7 & 0.99 & 0.94 & 1.05 & 0.82 & 0.99 & 0.88 & 1.11 & 0.83 \\
\hline \multirow[t]{9}{*}{$\mathrm{PM}_{2.5}$} & LO & 1.01 & 0.96 & 1.05 & 0.83 & 1.03 & 0.94 & 1.14 & 0.50 \\
\hline & L1 & 1.00 & 0.94 & 1.05 & 0.92 & 0.93 & 0.83 & 1.05 & 0.24 \\
\hline & L2 & 0.98 & 0.92 & 1.03 & 0.42 & 1.05 & 0.93 & 1.17 & 0.44 \\
\hline & L3 & 1.02 & 0.96 & 1.08 & 0.50 & 0.97 & 0.87 & 1.09 & 0.65 \\
\hline & L4 & 1.06 & 1.00 & 1.12 & $0.04^{\mathrm{a}}$ & 1.16 & 1.04 & 1.29 & $0.01^{a}$ \\
\hline & L5 & 0.98 & 0.93 & 1.03 & 0.43 & 0.89 & 0.79 & 0.99 & 0.04 \\
\hline & L6 & 0.98 & 0.93 & 1.04 & 0.49 & 0.95 & 0.85 & 1.07 & 0.38 \\
\hline & L7 & 1.01 & 0.96 & 1.05 & 0.82 & 1.04 & 0.95 & 1.15 & 0.38 \\
\hline & L1-7 & 1.01 & 0.97 & 1.06 & 0.57 & 0.99 & 0.91 & 1.08 & 0.87 \\
\hline \multirow[t]{6}{*}{$\mathrm{CO}_{\max }$} & LO & 1.00 & 0.99 & 1.00 & 0.61 & 1.00 & 0.99 & 1.01 & 0.79 \\
\hline & L1 & 1.00 & 0.99 & 1.00 & 0.25 & 1.00 & 0.99 & 1.01 & 0.96 \\
\hline & L2 & 1.00 & 1.00 & 1.01 & 0.61 & 1.00 & 0.99 & 1.01 & 0.69 \\
\hline & L3 & 1.00 & 1.00 & 1.01 & 0.18 & 1.00 & 0.99 & 1.01 & 0.57 \\
\hline & Ł4 & 1.00 & 1.00 & 1.01 & 0.16 & 1.01 & 1.00 & 1.02 & $0.03^{\mathrm{a}}$ \\
\hline & L5 & 1.00 & 0.99 & 1.00 & 0.09 & 1.00 & 0.99 & 1.01 & 0.71 \\
\hline
\end{tabular}

Table 4 Models with lagged and cumulative effects for suicides among four Colombian cities stratified by sex, 2011-2014 (Continued)

\begin{tabular}{|c|c|c|c|c|c|c|c|c|c|}
\hline \multirow[t]{3}{*}{ Pollutant } & \multicolumn{5}{|l|}{ Men } & \multicolumn{4}{|c|}{ Women } \\
\hline & \multirow{2}{*}{$\frac{\text { Lag }}{\text { L6 }}$} & \multirow{2}{*}{$\frac{\text { IRR }}{1.00}$} & \multicolumn{2}{|c|}{$95 \% \mathrm{Cl}$} & \multirow{2}{*}{$\frac{p}{0.95}$} & \multirow{2}{*}{$\begin{array}{l}\mathrm{IRR} \\
1.00\end{array}$} & \multicolumn{2}{|c|}{$95 \% \mathrm{Cl}$} & \multirow{2}{*}{$\frac{p}{0.41}$} \\
\hline & & & 1.00 & 1.01 & & & 0.99 & 1.01 & \\
\hline & L7 & 1.00 & 1.00 & 1.00 & 0.89 & 1.00 & 0.99 & 1.00 & 0.50 \\
\hline & L1-7 & 1.00 & 0.99 & 1.00 & 0.61 & 1.00 & 0.99 & 1.01 & 0.27 \\
\hline \multirow[t]{9}{*}{$\mathrm{O}_{3}$} & LO & 0.98 & 0.93 & 1.04 & 0.52 & 1.07 & 0.95 & 1.20 & 0.25 \\
\hline & L1 & 1.05 & 0.98 & 1.11 & 0.16 & 0.96 & 0.84 & 1.10 & 0.54 \\
\hline & L2 & 1.02 & 0.96 & 1.09 & 0.56 & 1.00 & 0.87 & 1.14 & 0.96 \\
\hline & L3 & 0.98 & 0.92 & 1.04 & 0.45 & 0.93 & 0.81 & 1.06 & 0.29 \\
\hline & $\llcorner 4$ & 1.02 & 0.95 & 1.08 & 0.62 & 1.04 & 0.91 & 1.18 & 0.59 \\
\hline & L5 & 0.97 & 0.91 & 1.03 & 0.33 & 0.98 & 0.86 & 1.12 & 0.75 \\
\hline & L6 & 1.05 & 0.98 & 1.12 & 0.14 & 0.97 & 0.85 & 1.11 & 0.65 \\
\hline & L7 & 1.01 & 0.96 & 1.00 & 0.63 & 1.04 & 0.93 & 1.17 & 0.49 \\
\hline & L1-7 & 1.05 & 1.00 & 1.10 & 0.05 & 0.97 & 0.88 & 1.07 & 0.52 \\
\hline
\end{tabular}

For each pollutant the IRR are mean changes in the rates per increase in this $20 \%$ of the average $\left(6 \mu \mathrm{g} / \mathrm{m}^{3}\right.$ for $\mathrm{NO}_{2}, 2 \mu \mathrm{g} / \mathrm{m}^{3}$ for $\mathrm{SO}_{2}, 0.4 \mu \mathrm{g} / \mathrm{m} 3$ for $\mathrm{CO}$ and $10 \mu \mathrm{g} / \mathrm{m}^{3}$ for $\mathrm{O}_{3}$ ). For $\mathrm{PM}_{10}$ and $\mathrm{PM}_{2.5}$, the values were centered by convention on 10 and $5 \mu \mathrm{g} / \mathrm{m}^{3}$, respectively. L1-L7 represent the cumulative effect of the moving average in the last 7 days

IRR incidence rate ratio, $\mathrm{Cl}$ confidence interval

Estimates are adjusted for temperature, precipitation, humidity and their lags

(from one day to up 7 days) as well as holidays

${ }^{a}$ No significant considering Bonferroni correction

important to consider the probability of misclassification and missing suicide data due to codification and diagnosis errors [31].

The present study serves to reduce the possible publication bias that can occur when researchers, reviewers and editors send or accept manuscripts based only on the strength or positivity of the findings [32]. Recognizing and preventing publication biased is an important task, both for the general scientific perspective (complete dissemination of knowledge) and for those who combine results from a number of similar studies (i.e., systematic reviews and meta-analyses) [32, 33]. Within this framework, our negative results therefore contribute to the available evidence regarding the relationship between pollution and suicide.

\section{Conclusions}

After adjusting for major confounding factors, we found no statistically significant association between air pollution and suicide in the four major Colombian cities. These "negative" results provide further insight into the current discussion regarding the existence of such a relationship. Employing a robust statistic approach and taking into account the main confounding factors, our study provides high quality evidence that could help clarify the relationship between air pollution and suicide. 


\section{Abbreviations}

CO: Carbon monoxide; DANE: National Administrative Department of Statistics (Departamento Administrativo Nacional de Estadística); ICD-10: International Classification of Diseases, tenth edition; IDEAM: Institute of Hydrology, Meteorology and Environmental Studies (Instituto de Hidrología, Meteorología y Estudios Ambientales); $\mathrm{MM}$ : Millimeter; $\mathrm{NO}_{2}$ : Nitrogen dioxide; $\mathrm{O}_{3}$ : Ozone; PM: Particulate matter; $\mathrm{PM}_{10}$ : Particulate matter $10 \mu \mathrm{m}$ or less in diameter; $\mathrm{PM}_{2.5}$ : Particulate matter $2.5 \mu \mathrm{m}$ or less in diameter; $\mathrm{SO}_{2}$ : Sulfur dioxide; VIT: Dispersion index

\section{Availability of data and materials}

The datasets used and analyzed during the current study are available from the corresponding author on reasonable request.

\section{Authors' contributions}

JAFN \& LARV: conception and design, JAFN, LARV \& VAFG: acquisition of data, analysis, and interpretation of data; JAFN, LARV \& CIAG: drafting the article and revising it critically for important intellectual content. All authors read and approved the final manuscript

\section{Ethics approval and consent to participate}

Not applicable

\section{Competing interests}

The authors declare that they have no competing interests.

\section{Publisher's Note}

Springer Nature remains neutral with regard to jurisdictional claims in published maps and institutional affiliations.

\section{Author details}

'Departamento de Salud Pública, Universidad del Norte, Barranquilla, Colombia. ${ }^{2}$ Servicios de Atención Psiquiátrica, Secretaría de Salud, Ciudad de México, Mexico. ${ }^{3}$ Departamento de Salud Pública, Universidad Industrial de Santander, Bucaramanga, Colombia.

\section{Received: 31 January 2018 Accepted: 2 May 2018}

Published online: 12 May 2018

\section{References}

1. Global Health Observatory $(\mathrm{GHO})$ data [http://www.who.int/gho/mental_ health/suicide_rates/en/\#].

2. WHO. In: Organization WH, editor. Preventive suicide. A global imperative. Geneva: Worl Health Organization; 2014

3. Cardona Arango D, Medina-Perez OA, Cardona Duque DV. Characterisation of suicide in Colombia, 2000 2010. Rev Colomb Psiquiatr. 2016, 45:170-7.

4. Kurokouchi M, Miyatake N, Kinoshita H, Tanaka N, Fukunaga T. Correlation between suicide and meteorological parameters. Medicina (Kaunas). 2015; 51:363-7.

5. Bando DH, Teng CT, Volpe FM, Masi E, Pereira LA, Braga AL. Suicide and meteorological factors in Sao Paulo, Brazil, 1996-2011: a time series analysis. Rev Bras Psiquiatr. 2017;39:220-7.

6. Ajdacic-Gross V, Bopp M, Ring M, Gutzwiller F, Rossler W. Seasonality in suicide-a review and search of new concepts for explaining the heterogeneous phenomena. Soc Sci Med. 2010;71:657-66.

7. Fernandez-Nino JA, Astudillo-Garcia Cl, Bojorquez-Chapela I, MoralesCarmona E, Montoya-Rodriguez AA, Palacio-Mejia LS. The Mexican cycle of suicide: a National Analysis of seasonality, 2000-2013. PLoS One. 2016:11: e0146495.

8. $\mathrm{Ng}$ CF, Stickley A, Konishi S, Watanabe C. Ambient air pollution and suicide in Tokyo, 2001-2011. J Affect Disord. 2016;201:194-202.

9. Yang AC, Tsai SJ, Huang NE. Decomposing the association of completed suicide with air pollution, weather, and unemployment data at different time scales. J Affect Disord. 2011;129:275-81.

10. Lin GZ, Li L, Song YF, Zhou YX, Shen SQ, Ou CQ. The impact of ambient air pollution on suicide mortality: a case-crossover study in Guangzhou, China. Environ Health. 2016:15:90.

11. Kim Y, Myung W, Won HH, Shim S, Jeon HJ, Choi J, Carroll BJ, Kim DK Association between air pollution and suicide in South Korea: a nationwide study. PLoS One. 2015;10:e0117929.
12. Bakian AV, Huber RS, Coon H, Gray D, Wilson P, McMahon WM, Renshaw PF. Acute air pollution exposure and risk of suicide completion. Am J Epidemiol. 2015;181:295-303.

13. Brunekreef B, Holgate ST. Air pollution and health. Lancet. 2002;360:1233-42.

14. Jayaraj RL, Rodriguez EA, Wang Y, Block ML. Outdoor ambient air pollution and neurodegenerative diseases: the Neuroinflammation hypothesis. Curr Environ Health Rep. 2017:4:166-79.

15. Babadjouni RM, Hodis DM, Radwanski R, Durazo R, Patel A, Liu Q, Mack WJ. Clinical effects of air pollution on the central nervous system; a review. J Clin Neurosci. 2017:43:16-24

16. Yackerson NS, Zilberman A, Todder D, Kaplan Z. The influence of airsuspended particulate concentration on the incidence of suicide attempts and exacerbation of schizophrenia. Int J Biometeorol. 2014:58:61-7.

17. Attademo L, Bernardini F, Garinella R, Compton MT. Environmental pollution and risk of psychotic disorders: a review of the science to date. Schizophr Res. 2017:181:55-9.

18. Afshari R. Reported association of air pollution and suicide rate could be confounded. Environ Health. 2017:16:16.

19. Guo Y, Barnett AG. Invited commentary: assessment of air pollution and suicide risk. Am J Epidemiol. 2015;181:304-8.

20. Bakian AV, Huber RS, Coon H, Gray D, Wilson P, McMahon WM, Renshaw PF. Bakian et al. respond to "assessing air pollution and suicide risk". Am J Epidemiol. 2015;181:309-10.

21. Bhaskaran K, Gasparrini A, Hajat S, Smeeth L, Armstrong B. Time series regression studies in environmental epidemiology. Int J Epidemiol. 2013;42:1187-95.

22. Ragguett RM, Cha DS, Subramaniapillai M, Carmona NE, Lee Y, Yuan D, Rong C, Mclntyre RS. Air pollution, aeroallergens and suicidality: a review of the effects of air pollution and aeroallergens on suicidal behavior and an exploration of possible mechanisms. Rev Environ Health. 2017;32(4):343-59.

23. Song F, Parekh S, Hooper L, Loke YK, Ryder J, Sutton AJ, Hing C, Kwok CS, Pang C, Harvey I. Dissemination and publication of research findings: an updated review of related biases. Health Technol Assess. 2010;14:1-193. iii, ix-xi

24. Cochran WG. Some methods for strengthening the common $\times 2$ tests. Biometrics. 1954;10:417-51.

25. Böhning D. A note on a test for Poisson overdispersion. Biometrika. 1994:81:418-9.

26. Armstrong BG, Gasparrini A, Tobias A. Conditional Poisson models: a flexible alternative to conditional logistic case cross-over analysis. BMC Med Res Methodol. 2014;14:122

27. Lu Y, Zeger SL. On the equivalence of case-crossover and time series methods in environmental epidemiology. Biostatistics. 2007;8:337-44.

28. Biermann T, Stilianakis N, Bleich S, Thurauf N, Kornhuber J, Reulbach U. The hypothesis of an impact of ozone on the occurrence of completed and attempted suicides. Med Hypotheses. 2009;72:338-41.

29. Kim C, Jung SH, Kang DR, Kim HC, Moon KT, Hur NW, Shin DC, Suh I. Ambient particulate matter as a risk factor for suicide. Am J Psychiatry. 2010; 167:1100-7.

30. Diez-Roux AV. Bringing context back into epidemiology: variables and fallacies in multilevel analysis. Am J Public Health. 1998:88:216-22.

31. OPS. Sobre la estimación de tasas de mortalidad para países de la Región de las Américas. In: Boletín Epidemiológico, vol. 24. Washington, DC: Organización Panamericana de la Salud; 2003.

32. Dickersin K. The existence of publication bias and risk factors for its occurrence JAMA. 1990:263:1385-9.

33. Tricco AC, Tetzlaff J, Sampson M, Fergusson D, Cogo E, Horsley T, Moher D. Few systematic reviews exist documenting the extent of bias: a systematic review. J Clin Epidemiol. 2008;61:422-34.

Ready to submit your research? Choose BMC and benefit from:

- fast, convenient online submission

- thorough peer review by experienced researchers in your field

- rapid publication on acceptance

- support for research data, including large and complex data types

- gold Open Access which fosters wider collaboration and increased citations

- maximum visibility for your research: over $100 \mathrm{M}$ website views per year

\section{At BMC, research is always in progress.}

Learn more biomedcentral.com/submissions 